\title{
LITERATURA E CULTURA NA SOCIEDADE DE MASSA: UM ESTUDO DAS OBRAS ELITE DA TROPA E TROPA DE ELITE ACERCA DA SEGURANÇA PÚBLICA
}

IONE NATALI XAVIER DE SOUZA Faculdade de Tecnologia e Ciências Vitória da Conquista, Bahia, Brasil E-mail: nattyxavier@hotmail.com

LUDIMILLA NOVAIS BONFIM Faculdade de Tecnologia e Ciências

Vitória da Conquista, Bahia, Brasil E-mail: ludimillanovais@hotmail.com

GUILHERME LOPES Faculdade de Tecnologia e Ciências Vitória da Conquista, Bahia, Brasil E-mail: galn1010@hotmail.com

GARDÊNIA JARDIM Faculdade de Tecnologia e Ciências Vitória da Conquista, Bahia, Brasil E-mail: gardeniajardim.ftc@gmail.com 
LITERATURA E CULTURA NA SOCIEDADE DE MASSA: UM ESTUDO DAS OBRAS ELITE DA TROPA E TROPA DE ELITE ACERCA DA SEGURANÇA PÚBLICA

Resumo: O presente artigo, elaborado por meio de pesquisa exploratória com levantamento bibliográfico e em campo, tem o propósito de discutir a respeito do livro Elite da Tropa e o filme Tropa de Elite, analisando qual seria a possível existência de um protótipo da ficção com a realidade da sociedade, no que se refere à segurança pública. Para tal feito, delimitou-se como objetos de estudo, comandantes militares, docentes e discentes do curso de Direito.

Palavras-Chaves: Literatura; segurança pública; sociedade.

LITERATURA Y CULTURA EN LA SOCIEDAD DE MASAS: UN ESTUDIO DE LAS OBRAS DE LAS TROPAS DE ELITE Y TROPAS DE ELITE POR LA SEGURIDAD PÚBLICA

Resumen: Este artículo, elaborado por medio de la literatura de investigación exploratoria y en el campo, tiene la intención de discutir sobre el libro y la película Tropa Elite Tropa de élite, analizando cuál sería la posible existencia de un prototipo de ficción con realidad de la sociedad en materia de seguridad pública. Por esta hazaña, fue delimitado como objeto de estudio, los comandantes militares, profesores y alumnos de la escuela de leyes. Palabras clave: Literatura, la seguridad pública, la sociedad.

LITERATURE AND CULTURE IN MASS SOCIETY: A STUDY OF THE WORKS OF ELITE TROOPS AND ELITE TROOP ABOUT PUBLIC SAFETY

\begin{abstract}
This article, prepared by means of exploratory research literature and in the field, is intended to discuss about the book and the film Troop Elite, analyzing what would be the possible existence of a prototype of fiction with reality society with regard to public safety. For this feat, was delimited as objects of study, military commanders, teachers and students of the law school.
\end{abstract}

Keywords: Literature; public safety; society. 


\section{INTRODUÇÃO}

Elite da Tropa é uma composição literária que foi adaptada para o cinema e relata a situação da segurança pública do Estado do Rio de Janeiro. Os fatos relatados nas obras apresentam uma realidade lastimável da cidade "maravilhosa", onde grande parte do sistema funciona para se manter perpétuo, envolvendo políticos indignos, policiais corruptos, traficantes e consumidores de drogas, e uma sociedade com segurança pública bastante questionável. Seria possível afirmar que, tanto o livro quanto o filme são protótipos quando comparados com a realidade no que se refere à segurança pública brasileira?

O ambiente desfavorável, cujo nível da corrupção já chegou ao estágio de êxtase, não colabora de modo algum, para o que deveria ser as práticas adequadas no combate ao crime. Entretanto, os baixos salários, e a falta de melhores condições de trabalho e infraestrutura influenciam de uma maneira negativa nos serviços prestados à sociedade. A falta de educação de qualidade, também é um fator primordial, que contribui efetivamente para a formação de conduta de indivíduos delinquentes.

Contudo, isso não quer dizer que os meios utilizados pelo Bope - BataIhão de Operações Policiais Especiais - sejam merecedores de elogios, visto que, o Batalhão apenas apresenta como é a realidade: guerra é guerra.

A política como fator influente nas decisões do "sistema" e a disparidade entre as classes sociais são possíveis variáveis no serviço prestado à sociedade.

Não é por acaso que o filme atingiu uma das maiores bilheterias na história da cinematografia brasileira. Nesse sentido, pode-se afirmar que Tropa de Elite, além de um fenômeno cultural, é igualmente um exemplo de fator social, uma vez que o Brasil é um país marcado por uma profunda desigualdade social, consequência de uma política oligárquica de concentração de renda despropositada. Entende-se por Brasil assim, desde 1500, dispondo em maioria de autoridades que fazem descaso com a educação, saúde, violência, segurança pública e outras séries de questões que deveriam ser debatidas com mais prioridades.

Segundo Abreu (1996, p. 233), "não obstante as mudanças dos padrões emergentes de criminalidade urbana violenta, as políticas de segurança e justiça criminal, formuladas e implementadas pelo governo democrático, não se diferenciam grosso modo daquelas adotadas pelo regime autoritá- 
rio.". Desse modo, é permitido dizer que se tem um "Estado para pobres" com menos assistência, mais cobranças e controle, e um "Estado para ricos" com mais possibilidades e resistente a mudanças democráticas que possam porventura enfraquecer o poder estatal.

Portanto, partindo do pressuposto de que as obras abordam pontos inerentes da sociedade, com visão de mundo particular, seria aceitável sim, dizer que as mesmas são paradigmas no que diz respeito à realidade da segurança pública no Brasil, uma vez que, os salários pífios dos policiais, a falta de melhores condições de trabalho e infraestrutura adequada, entre outros, uma vez que influenciam diretamente de nos serviços prestados.

\section{LITERATURA E CULTURA NA SOCIEDADE DE MASSA}

A cultura passou por várias definições desde o século XVI, pois a mesma está ligada a vários sentidos como, por exemplo, educação, formação acadêmica, costumes de povos e regiões, cerimônias clássicas, lendas, mitos e crenças, manifestações artísticas, pintura, escultura, literatura, enfim, uma forma genérica de caracterizar a sociedade.

De qualquer modo, é possível sintetizar tudo em duas concepções de cultura. "A primeira concepção de cultura remete a todos os aspectos de uma realidade social; a segunda refere-se mais especificamente ao conhecimento, às ideias e crenças de um povo" (SANTOS, 1996, p. 23). É plausível de afirmação que nenhuma cultura deve se considerar mais elevada que outra, pois cada uma tem a sua especificidade.

Segundo Geertz (1973, p. 24) cultura é um modo de vida, "a cultura não é um poder, algo ao qual podem ser atribuídos casualmente os acontecimentos sociais os comportamentos, as instituições ou os processos; ela é um contexto, algo dentro do qual eles (os símbolos) podem ser descritos de forma inteligível - isto é, descritos com densidade.". Seguindo esse pensamento de Geertz é permitido justificar que a "cidade maravilhosa" é vista culturalmente como a cidade do Samba, da Bossa Nova, da Garota de Ipanema, entretanto, é também vista como a cidade da violência, dos morros, dos traficantes e da corrupção. O fato é que essas realidades apresentadas são divergentes entre si, mas fazem parte da cultura de um "mesmo espaço" na sociedade carioca, ou seja, é pertinente dizer que ambas são modo de vida cultural. 


\subsection{Elite da Tropa e Tropa de Elite}

O livro Elite da Tropa narra os fatos ocorridos nas operações do BataIhão de Operações Policiais Especiais - BOPE - especificamente na cidade do Rio de Janeiro, de forma detalhada e minuciosa, dissecando os principais pontos que envolvem a falta de interesse dos policiais para com a segurança pública e o descaso do Estado com a sociedade.

Entretanto, o livro não tem como propósito depreciar os profissionais da segurança pública, pelo contrário, o objetivo é fazer com que os policiais reflitam a respeito do cenário crítico, juntamente com a opinião pública e que o Estado e demais instituições ligadas ao mesmo, promovam um aperfeiçoamento capaz de reestruturar a situação da segurança pública do país. "Eles são máquinas de guerra e foram treinados para ser a melhor tropa urbana do mundo, um grupo pequeno e fechado de policiais atuando com força máxima e devastadora." (SOARES, 2005).

Todavia, o filme Tropa de Elite, minimiza alguns fatos detalhados, no entanto remete a mensagem com mais facilidade de ser compreendida, uma vez que imagens têm um poder de persuasão muito maior e facilita a similitude da violência urbana na sociedade. A enorme repercussão de Tropa de Elite se baseia justamente, entre outros fatores, na destreza de adaptar um livro relativamente complexo em um filme com questões que são de interesse da sociedade de maneira que deixa o telespectador entretido e pensante.

Segurança, de acordo com o dicionário Aurélio 2011, é oriundo de segurar, explana a ação e efeito de tornar seguro ou de assegurar algo, alguma coisa ou alguém. De modo igual, segurança indica o sentido de tornar livre de perigos. Seguridade tem o mesmo sentindo, uma vez que é a qualidade, a condição de estar seguro e livre de ameaças, de estar longínquo de danos ou prejuízos contingente.

E o que poderia ser dito a respeito de Segurança Pública? Segundo o professor De Placido e Silva no Vocabulário Jurídico (1963, p.18) "é o afastamento, por meio de organizações próprias, de todo perigo ou de todo mal que possa afetar a ordem pública, em prejuízo da vida, da liberdade ou dos direitos de propriedade de cada cidadão." Adotando a afirmação anterior, as obras de Elite não apresentam comportamento tão favorável para com a sociedade, visto que o poder e a influência são utilizados para diversos fins pessoais e muito pouco para os fins de verdade e de fato necessários, que envolve diretamente a preservação da segurança do cidadão e da sociedade. 
Tropa de Elite procurou delinear em uma extensa proporção como é o trabalho do BOPE e soube retratar muito bem a violência na cidade do Rio de Janeiro, concentrando-se nas famosas favelas que são comandadas pelo tráfico, nos usuários de drogas (que não são somente os favelados, pelo contrário, quem financia em parte as drogas, são os jovens de classe médiaalta) e na elevada corrupção existente dentro da polícia civil. Essa é mais uma razão para a enorme repercussão das duas edições cinematográficas de Tropa de Elite. Em nenhum momento no Brasil, houve um filme nacional de tanto sucesso, visto antes mesmo de ser exibido nos cinemas. Sua versão pirateada foi visualizada em média por 15 milhões de pessoas.

Ainda assim, os dois meios de exibições, tanto o livro quanto o filme aplica-se em relatar o contexto dos acontecimentos contemporâneo da cidade 'maravilhosa' no que se atribui à segurança pública, policial e do Estado, cujas modificações são necessárias estruturação dos mesmos, visto que segurança pública é uma demanda social que requer de estruturas estatais e demais corporações da sociedade para ser bem-sucedida e efetiva.

\section{DESENVOLVIMENTO}

\subsection{Metodologia}

No que se refere à tipologia optou-se inicialmente por pesquisa exploratória com base em levantamento bibliográfico em livros, filme, artigos científicos e sites. De acordo com Gil (2002, p.41), "a pesquisa exploratória proporciona maior familiaridade com o problema, com vistas a torná-lo mais explícito ou construir hipóteses.".

Para Lakatos e Marconi (1987) a pesquisa bibliográfica é realizada com base em registros de toda bibliografia já divulgada a respeito do objeto de pesquisa, constituído principalmente de livros, revistas, artigos de periódicos, teses, monografias, entre outros. Esse método consiste em subsumir o pesquisador das mais diversas referências existentes do material, a fim de que o mesmo tenha um bom embasamento na elaboração do projeto de pesquisa.

Para determinar a população, elegeu-se como objetos de estudo comandantes militares das unidades especializadas da cidade de Vitória da Conquista - BA, docentes e discentes do curso noturno, do sétimo e oitavo semestre de Direito da Faculdade de Tecnologia e Ciências de Vitória da Conquista - BA. Foram analisados três, seis e dezesseis sujeitos respectivamente. Optou-se por estudo censitário, uma vez que $100 \%$ de cada população 
foram analisadas, sendo irrelevante a mensuração da amostra. De acordo com Lakatos (1992, p.108) "amostra constitui uma porção ou parcela, convenientemente selecionada do universo (população)." Em pesquisas com população sintetizada, é mais viável utilizar-se de pesquisa censitária, visto que a amostra seria aproximadamente o todo da população.

Para a coleta de dados, a mesma teve como base, questionários fechados para os discentes e entrevistas para os comandantes militares e os docentes. Para Lakatos e Marconi (1991) questionário é uma sequência de perguntas elaboradas e ordenadas, a fim de levantar informações a respeito do tema pesquisado, de modo que não de margem a casualidade no conteúdo proposto. Segundo GIL (2002, p. 115), “entrevista é a técnica de coleta de dados em que o investigador se apresenta frente ao entrevistado (gestores) e lhe formula perguntas com o objetivo de obter os dados que interessam a uma investigação". As entrevistas permitem respostas subjetivas, ou seja, de teor qualitativo. Segundo Minayo (1995, p.21), "a pesquisa qualitativa responde a questões muito particulares. Ela se preocupa, nas ciências sociais, com um nível de realidade que não pode ser quantificado, ou seja, ela trabaIha com o universo de significados, motivos, aspirações, crenças e valores".

\subsection{Resultados e discussões}

Com relação aos resultados alcançados a partir da pesquisa qualitativa, a transcrição das entrevistas possibilitou uma compreensão mais ampla no que se refere à segurança pública. Entendeu-se que segurança pública perpassa por uma série de questões até chegar de fato na mesma.

No que se refere às entrevistas realizadas com os comandantes militares, foi possível observar que é unânime o entendimento de que Segurança Pública não é um problema somente de ordem policial e sim de fator social, que acompanha a falta das diversas necessidades básicas do homem como é previsto nos direitos humanos, onde os mesmos afirmam que "todos os seres humanos nascem livres e iguais em dignidade e direitos", entretanto isso não se aplica de fato na realidade.

Quando perguntado a um dos comandantes militares entrevistados a respeito da prestação de serviço da segurança pública, se a mesma é feita de uma forma igualitária, o mesmo afirmou que: 
diferenças de tratamentos não só na área da segurança pública, mas nas áreas mais básicas do convívio social. Nós vemos as discriminações no tratamento de pessoas, nos vemos isso na área de saúde, na prestação de serviço jurisdicional onde o acesso à justiça é limitado aos que tem poder. $O$ acesso das pessoas menos favorecidas se restringe apenas a parte criminal, onde os acessos às áreas juristas de direitos coletivos, direitos individuais, elas são subjugadas a segundo e terceiro plano por conta do acesso não ser democrático de forma igualitária para todos. Então falar de tratamento igualitário e segurança pública, a gente não pode dissociar segurança pública de outros setores. Então eu vejo ainda o tratamento de forma igualitário na prestação de serviço público como um todo muito desigual. (REPRESENTANTE DA SEGURANÇA PÚBLICA, 2013).

É necessário perceber que as condições sociais oferecidas para sociedade é de contraste evidente, posto que, uma pequena parcela usufrui de diversos benefícios, independente de serem de direito ou não, enquanto a maior parte da população é composta por pessoas de baixa renda, que corresponde por semianalfabetos, moradores de ruas, ocupantes de presídios, viciados em drogas etc., portanto, esses fatores não seriam apenas mera coincidência. Daí um dos motivos da segurança pública não ser prestada de modo imparcial.

Quanto à "miséria”, violência social e a consequência de geração de outros problemas, todos os comandantes concordaram que esses fatores são preponderantes para que o indivíduo venha se tornar um "meliante" diante das circunstâncias em que se encontra. Nos bairros mais pobres é visível a quantidade de crianças soltas nas ruas, que ficam a mercê de oportunidades ilícitas. "Os jovens estão sendo capturados pelo tráfico deliberadamente e muita das vezes acontece por falta de interesse e ações efetivas por parte do Estado Governamental". (REPRESENTANTE DA SEGURANÇA PÚBLICA, 2013). A violência social, para alguns, é percebida como causa do caos e da tragédia urbana que competiria à segurança pública eliminar, no entanto, a segurança pública é uma alíquota, que faz parte do Estado, e a constatação da ausência do mesmo em diversas áreas sociais é que da condição para que os encarregados em manter a segurança, faltem com seu papel. Entre verdades e equívocos, parece lógico admitir que a violência é o espectro que, além de assombrar, afronta a segurança pública de tal modo, que coloca em risco a segurança de todos.

No questionamento a respeito da falta de interesse dos policiais no combate ao tráfico, a maioria das respostas seguiu uma linha de raciocínio 
semelhante, onde as leis não são bem amarradas, bem elaboradas. Existem diversas lacunas nas leis, que impedem a polícia de fazer um trabalho de maneira eficaz. "A legislação do nosso país é um grande desestímulo para o trabalho policial. A gente trabalha, a gente prende, a gente se arrisca e a gente vê que a resposta do ponto de vista jurídico é extremamente benevolente". (REPRESENTANTE DA SEGURANÇA PÚBLICA, 2013).

Em relação à importância das obras Elite da Tropa e Tropa de Elite para a sociedade, os comandantes responderam que as mesmas são de suma importância, pois possibilitam as pessoas a "galgarem" em um ambiente repleto de informações que antes só eram vistas por meios de jornais e reportagens, muitas vezes de forma sensacionalista. No que concerne ao filme especificamente, os comandantes militares acreditam que muitos fatores são típicos da cidade do Rio de Janeiro, principalmente o alto nível de corrupção existente na corporação da polícia, uma vez que não é negável a existência dessa corrupção em outros estados, entretanto na "cidade maravilhosa" é bem mais evidente, dado que, a quantidade de favelas é bastante numerosa, o que propicia várias formas de fazer barganhas, onde é possível apontar a má remuneração como condição para tal prática, uma vez que é sabido que, policias põe suas vidas em riscos para receberem salários que não são suficientes para proporcionarem bem estar e tranquilidade para os mesmos.

Quanto à prioridade da segurança pública em uma escala de necessidade básica, os comandantes militares enxergam que existem vários fatores que corroboram para que a segurança pública não tenha prioridade mínima necessária, visto que a educação e a saúde, também não tem a estrutura ideal para que o país se desenvolva plenamente.

É sabido que existe, incluso na maioria das corporações a formação de milícias, e de acordo com os comandantes, essa é mais uma lacuna deixada pelo Estado, na falta de estrutura relevante para os polícias, além do fator caráter, pois a formação de caráter é uma questão a parte. Essa declaração fica evidenciada na afirmação de um dos comandantes militares:

A gente volta aquele ponto da formação do ser humano. Por mais que você eduque, instrua, por mais que você reprima, sempre vai ter gente cometendo crime. A gente tem juiz, desembarcador, deputado, senador e o policial. Cada um dentro de sua esfera, então, no caso do policial ele vai partir exatamente pra vender a segurança, pra fazer milícias, essas coisas, que é o que está na área de atuação dele. (REPRESENTANTE DA SEGURANÇA PÚBLICA, 2013). 
Foi perceptível de forma predominante entre os comandantes, que a situação atual da segurança pública no país (de maneira geral) se deve à ausência do Estado, não somente com segurança, mas em todas as áreas sociais que possibilita o cidadão dignidade. Para os comandantes, segurança pública, por si só, não resolve a situação existente de caos na sociedade, já que a mesma não é a "solução milagrosa" para todos os problemas sociais.

No que concerne às entrevistas realizadas com a população dos docentes foram observadas opiniões divergentes em relação à prestação dos serviços da segurança pública. Entretanto, foi assistido um consenso dos docentes, junto aos comandantes militares no que se refere à falta de atenção do Estado para com a segurança e outras áreas públicas da sociedade.

Quando os docentes foram questionados a respeito da falta de qualidade de segurança pública e à falta de uma infraestrutura adequada, os mesmos evidenciaram falhas que compete ao Estado "ajustar". Determinado docente afirma que:

[...] A segurança pública não tem como dar conta de todos os problemas sociais. Ela tem condição apenas de dar conta de um dos problemas que é a manifestação deles, então a ausência de educação, de saúde, de dignidade, de alimentação leva ao crime. A segurança pública contém a consequência e não a causa. Então por isso eu diria que a segurança pública não tem condições de ser eficaz. (DOCENTE DO CURSO DE DIREITO, 2013).

Com a afirmativa do docente a respeito da ausência de diversos fatores sociais, o mesmo comprova que essa percepção não vem somente dos comandantes, uma vez que os mesmo concordam com essa linha de raciocínio.

No que se refere à existência de diversas "milícias policias", a "cumplicidade" do Estado com esse comportamento e com uma possível modificação no quadro atual, os professores de Direito, acreditam que é possível reverter esse quadro, mas são necessárias medidas eficientes como aumento de salário, fiscalização eficaz, políticos que se interessem de fato pela sociedade, a fim de um bem comum, e não em interesses individuais, assim como, infraestrutura adequada para o aparato policial. Entretanto, todas essas medidas cabem ao Estado, ou seja, a realidade é que para ter segurança de qualidade e menos corrupção na corporação é preciso que o Estado seja de fato efetivo em diversos âmbitos da sociedade e por consequência, eliminar 
dos cargos, os políticos que não "permitem" que as coisas caminhem. "Não basta apenas o aumento de salários, é imprescindível que a fiscalização seja mais intensa dentro da corporação e a punição dessas milícias seja efetiva e mais severa". (DOCENTE DO CURSO DE DIREITO, 2013). Para outro docente a questão vai um pouco mais além.

A polícia está vinculada ao chefe do poder executivo, estadual, federal. Então o que acontece, a polícia federal tem condições de trabalho, por isso é mais eficiente, tanto que as investigações sempre cominam em alguma prisão. São bem mais eficazes. Agora, a polícia federal tem além de equipamentos de primeira qualidade e treinamento, tem um ótimo salário, a remuneração é alta. Eu não estou dizendo que aquele que recebe pouco deve ser corrupto não, mas acontece que a realidade da polícia militar e da civil é bem diferente. $O$ policial militar recebe em média um salário de $\mathrm{R} \$$ 1.200 .00 reais, em Brasília um pouco mais, $R \$ 4.000,00$ em média. Bem, em Brasília a polícia militar é a menos corrupta. Eu não sei se isso é uma coincidência. O policial militar ele tem filho, tem muIher, constitui família. Com um salário de $\mathrm{R} \$ 1.200,00$ à $\mathrm{R} \$ 2.000,00$ reais (sendo que $R \$ 2.000$,00 reais são quando ele faz parte da tropa de elite da polícia militar) ele consegue no máximo morar a cem metros do traficante. Por que com $\mathrm{R} \$ 1.200,00$ ele acaba morando na favela também. Então ele convive com o traficante, ele tá submisso ao traficante, as vezes ele é até amigo do traficante, porque é da favela. Ele tem medo de morrer quando entra na favela e ai começa. E com medo, ele não faz o trabalho bem feito. Por medo, ele se corrompe, ou às vezes por necessidade. Isso é política pública. Se o político falar, "pera aê" vou parar de furtar e vou investir. (DOCENTE DO CURSO DE DIREITO, 2013).

Em relação à "prestação de serviço" de segurança privada, ofertada pelos policiais, apesar de, dois professores concordarem que é ilegal o exercício da mesma, as respostas foram distintas, fator que diverge das opiniões dos próprios comandantes, uma vez que, todos afirmaram que é ilegal por lei, a prestação de segurança privada, seja por policiais, delegados, comandantes militares ou qualquer componente do aparato policial. O docente afirma que segurança privada "não pode ser prestada por aqueles que têm por dever prestar a segurança pública, como os delegados, pois a estes incumbe assegurar a segurança de todos, sem qualquer contraprestação.". Entretanto tem docente que não dispõe de uma afirmativa, pois o mesmo como profissional de Direito não pode considerar apenas o que é mostra- 
do na mídia, é preciso de fato ter conhecimento a respeito. Contudo, tem docente que acha "correto", visto que não fica registrado, mas todo mundo sabe. "Não pode, mas tem. Porque pra ele é interessante não proteger determinado bairro de rico, porque o rico vai lá e compra o serviço na mão dele. Virou um grande comércio." (DOCENTE DO CURSO DE DIREITO, 2013).

No que concerne, ao tráfico de drogas e as possíveis maneiras de um combate eficaz para a "eliminação" do problema, as opiniões foram divergentes em vários aspectos, desde estruturação familiar (medidas sociais), tratamento em clínicas, oferecido gratuitamente para aqueles que não podem pagar, até legalização das drogas, uma vez que, o álcool também é um tipo de droga (se não for a pior de todas) e é legalizado. Empenho efetivo contra o crime de forma geral, também foi citado como maneira de melhoria, visto que, a sociedade é constituída por indivíduos perversos, independente das condições que lhe são oferecidas, partido da análise que existe o envolvimento de pessoas de alto nível (em diversas áreas sociais) com conduta ilícita.

Quanto à droga ser via de sobrevivência para muitos moradores da favela, a maioria dos docentes afirmou que essa é uma opção "justificável” levando em consideração o meio convivido e a ausência do Estado em vários aspectos sociais. "É onde o Estado se ausenta e alguém ocupa o espaço [...]. As pessoas moradoras têm que se adaptar a essa situação e acabam "aceitando" e se submetendo ao tráfico de drogas para sobreviver e para viver a vida delas do dia a dia.". (DOCENTE DO CURSO DE DIREITO, 2013).

Com relação aos resultados alcançados a partir da pesquisa quantitativa, a tabulação de dados possibilitou ao grupo uma compreensão bem mais ampla no que se refere à segurança pública. Entende-se que segurança pública perpassa por uma série de questões até chegar de fato na mesma.

Ao questionar os discentes do curso de direito acerca da necessidade de reformas na segurança pública, foi observado que $73 \%$ acreditam na ausência de infraestrutura adequada para uma segurança de fato efetiva, enquanto mais de $20 \%$ concordam em parte.

É plausível que a maioria dos discentes concorde (de maneira total ou parcial) com o fato da segurança pública necessitar de reforma e de nova reestruturação para possível melhoria na prestação de serviço ofertada pela polícia, visto que é notório o "descaso" na prestação de serviço disponibilizada para a sociedade, tanto por parte da policia quanto por parte do Estado. Entretanto, ao se deparar com acadêmicos que serão futuros profissionais da lei, que não concordam de forma alguma com a necessidade 
de reforma, é questionável saber o porquê. Então é aceitável dizer que essa minoria, seria aquela parcela da sociedade que não enxerga esse primordialidade como um fator relevante, uma vez que sua classe e nem seus interesses estão sendo afetados, portanto, não é algo preocupante.

No que se refere, ao problema da violência envolver simultaneamente diversas esferas da vida social, como emprego e renda, saúde, educação, classes sociais, urbanização e demais fatores, os discentes acreditam em sua maioria (93\%) que é a violência é um reflexo da falta dos elementos básicos de uma vida social decente.

Qual seria a relação de miséria e violência? Em suma, acredita-se tratar de relação simples e direta, e as estatísticas são suficientes para provar, dado que o índice de violência da sociedade está ligado proporcionalmente à falta de mínimas condições de sobrevivência do homem, já que pessoas de baixa renda correspondem a uma grande parcela que não tem acesso a educação, saúde, emprego e renda e moradia no mínimo decente e acabam encontrando no crime a "oportunidade" de uma realidade diferente, ou seja, de vida "satisfatória".

No que diz a respeito à realidade da segurança pública do país ser uma espécie de personificação da situação relatada no filme Tropa de Elite, tem se aprovação "positiva" em concordância, visto que 53\% concordam sem nenhuma objeção e os outros $47 \%$ dos discentes concordam parcialmente.

Pode-se associar essa concordância, a diversos fatores sociais já citados, mas principalmente devido às práticas policiais estarem relacionadas, em maioria, a interesses políticos ao invés de interesses da sociedade, que paga com os impostos - altíssimos, diga-se de passagem - por uma segurança pública de qualidade e recebe em troca uma segurança que "esquece" os menos favorecidos e da priori a elite, podendo ser observado esse dado, na passagem do Papa pelo Brasil. Mas como já foi dito, o problema não é só de ordem policial, o Estado também (se não for o principal) tem participação direta nessa personificação da sociedade brasileira, visto que, é evidente a falta de investimento em educação, saúde e demais ações sociais efetivas para com a sociedade.

Para mais de $90 \%$ dos discentes, mesmo com algumas possíveis ressalvas, os policiais que fazem parte das milícias, são fortes parceiros do crime e do tráfico de drogas.

As milícias, que são "organizações" constituídas por policiais e até mesmo, ex-policiais, utilizam do seu prestígio para fazer praticas de extorsão, muitas vezes de via dupla, tanto com moradores quanto com os traficantes - 
no caso dos traficantes não seria bem uma extorsão e sim interesses de ambas as partes. Com os moradores da comunidade, as milícias passam a impor sua vontade e passam a ter um controle equivalente aos traficantes do morro. As milícias impõem medo junto aos moradores, forçando os mesmos a pagarem propina por "segurança”, bujão de gás, controle no transporte entre outros. No que diz respeito aos traficantes, os milicianos fazem vistas grossas com relação ao tráfico e negocia armas de alto porte, recebendo pagamentos diversas vezes superiores aos seus salários no final do mês, o que poderia ser uma possível justificativa para suas praticas.

Para $67 \%$ dos discentes a desvalorização dos policiais, é uma justificativa para que os mesmos fiquem suscetíveis à corrupção ou qualquer tipo de "sedução de vias fáceis" oferecido pelas milícias. Enquanto que para 33\% corrupção não tem justificativa. Esse ponto é pertinente para discursão, visto que mais de dois terços dos discentes têm postura que favorece os possíveis deslizes dos policiais. Levando em consideração que policiais, antes de qualquer coisa são seres humanos, os mesmos também têm família e compromissos a serem pagos, e quem sabe a concordância da maioria, seria a respeito de transações que envolvem somente traficantes e não moradores, pois dessa forma as milícias não estariam ameaçando as famílias de bem que vivem nas comunidades e nos morros. Mais um quesito a ser analisado é o interesse do Estado em ter baixas ocorrências nas comunidades e nas favelas. Se policiais e traficantes entram em acordo, não "existem" confrontos e tiroteios, o quê para o Estado é uma situação bastante positiva em dois sentidos, a "diminuição" da violência e consequentemente queda em greve de policiais por ajuste de folha, posto que os mesmos "fazem" seus salários extras por fora.

No que se refere a uma nova estrutura organizacional e outras possíveis medidas, "apenas" $54 \%$ dos discentes acreditam que essas mudanças colaborariam de forma efetiva para uma melhor segurança. É questionável saber por que "apenas" $54 \%$ concordaram que uma nova estrutura, corroboraria de forma positiva em melhorias na segurança pública, uma vez que, $73 \%$ acreditam na falta de infraestrutura adequada para a segurança pública quando questionados anteriormente. É admissível dizer que se há ausência de uma base adequada é preciso reformas, visto que nem sempre é disposto aos policiais equipamentos de combate devidos, investimento em diversos (ou mais) programas que oferecessem palestras com foco em redução e prevenção à violência, melhorias significativas na remuneração, com plano 
de carreira satisfatório, como maneira de incentivar a prestação de serviço com qualidade e imparcialidade, e também como forma de inibir a corrupção na corporação militar, portanto uma nova estrutura organizacional seria ideal, dado que a segurança pública é necessária para a ordem e funcionamento adequado da sociedade no cotidiano, devido à capacidade da mesma em controlar e prevenir o crime.

\section{CONSIDERAÇÕES}

Este artigo tem relevância significativa, por apresentar (mesmo que de maneira sucinta) pontos de vistas, de profissionais que estão intimamente ligados à segurança pública e como ilação, forneceram reflexões para saber que não se analisa segurança pública como fato isolado, em razão da mesma envolver questões complexas ligadas à exclusão social, racial e cultural, dessa maneira é preciso observar as várias vias que norteiam a condição atual da segurança.

Tropa de Elite assim como outros filmes nacionais, como, por exemplo, Cidade de Deus, Cidade dos Homens e Era Uma Vez, procuraram retratar o cotidiano da sociedade com enfoque em determinados problemas sociais, que servem como objetos de estudos.

Por meio dessa análise foi permitido, inferir que a situação da segurança pública envolve uma série de questões que vão além da visão periférica do revés.

A ausência da atuação efetiva do poder público, com sua representação de autoridade, nas diversas áreas sociais, como por exemplo, educação, emprego e renda, moradia, saúde básica, esporte, lazer, e outros diversos pontos que possibilitam o homem de ser digno, tende a colaborar com fatores que implicam diretamente na situação vigente da segurança pública.

É indiscutível que o método de estruturação da política de segurança pública, requer rupturas, novos modelos de paradigmas, sistematização de ações eficazes e satisfatórias, acordada com programas sociais sólidos, efetivos e contínuos, e principalmente fincados na valorização do ser humano sob todas as particularidades, levando em deferência os contextos sociais de cada cidadão. Por diversas razões, dispondo desse estudo, em suma, o crime pode muito bem "compensar" para alguns.

Mediante a todas essas questões que afligem, não somente o Rio de Janeiro, as obras em citadas, tem o condão de demonstrar a realidade da segurança pública na sociedade brasileira como um todo. 


\section{REFERÊNCIAS}

ABREU, Sérgio França Adorno. A gestão urbana do medo e da insegurança: violência, crime e justiça penal na sociedade brasileira contemporânea. Mar. 1996. Disponível em: < http://www.nevusp.org/downloads/down187.pdf> Acesso em: 03 Set. 2013.

CALDAS, Waldenir. A literatura da cultura de massa: uma análise sociológica. Ridendo Castigat. São Paulo, 2000. . (1987). Cultura de massa e cultura de comunicações. 2 ed. Global. São

Paulo, 1991.

DE PLÁCIDO E SILVA, Oscar Joseph. Vocabulário jurídico. Rio de Janeiro: Forense, 1963. V. IV.

GEERTZ, Clifford. A interpretação das Culturas. Zahar. Rio de Janeiro, 1973.

GIL, Antônio Carlos. Como elaborar projetos de pesquisa. São Paulo: Editora Atlas, 2002.

LAKATOS, Eva Maria; MARCONI, Marina de Andrade. Fundamentos de metodologia científica. 3. ed. São Paulo: Editora Atlas, 1991. . (1987). Metodologia do trabalho científico 3. ed. São Paulo: Editora

Atlas, 1987.

MINAYO, M. C. S. (Org.). Pesquisa Social: teoria, método e criatividade. Petrópolis: Vozes, 1995.

PADILHA, José; PRADO, Marcos. Tropa de Elite. Brasil, Universal Pictures do Brasil. [DVD] Ação/Drama. 115 min. 2007.

SANTIAGO, Silviano. Literatura e cultura de massa. Mar. 1994. Disponível em $><$ http://literaturaponto.files.wordpress.com/2011/03/silviano-santiago-literatura-e-cultura-de-massa. pdf> Acesso em: 26 Mar. 2012.

SANTOS, José Luiz. O que é cultura. 16ed. Brasiliense. São Paulo, 1996.

SILVA, Fernando Moreno. Cultura e mercado: o best-seller em questão. INTERthesis, dez., 2006. Disponível em:<www.periodicos.ufsc.br/index. php/interthesis/article/ view/795> Acesso em: 24 Mar. 2012.

SOARES, Luiz Eduardo. BATISTA, André. PIMENTEL, Rodrigo. Elite da Tropa. Objetiva. Rio de Janeiro 2005.

TAVELA, Maria Cristina Weitzel. Literatura de massa na formação do leitor literário. 2010. http://www.uff.br/darandina/files/2010/12/16-Literatura-de-massa-na-forma\%C3\%A7\%C3\%A30-do-leitor-liter\%C3\%A1rio.pdf>Acesso em 26 Mar. 2012. 


\section{Ione Natali Xavier de Souza}

Graduando em Comunicação Social com habilitação em Publicidade e Propaganda na Faculdade de Tecnologia e Ciências Campus de Vitória da Conquista - BA. Cursando o $6^{\circ}$ semestre. E-mail: nattyxavier@hotmail.com

\section{Ludimilla Novais Bonfim}

Graduando em Comunicação Social com habilitação em Publicidade e Propaganda na Faculdade de Tecnologia e Ciências - Campus de Vitória da Conquista - BA

Cursando o $6^{\circ}$ semestre.

E-mail: ludimillanovais@hotmail.com

\section{Guilherme Lopes}

Graduando em Comunicação Social com habilitação em Publicidade e Propaganda na Faculdade de Tecnologia e Ciências - Campus de Vitória da Conquista - BA

Cursando o $6^{\circ}$ semestre.

E-mail:galn1010@hotmail.com

\section{Gardênia Jardim}

Graduada em Turismo pela Faculdade de Tecnologia e Ciências / Vitória da Conquista - BA (2008). Mestre em Cultura e Turismo pela Universidade Estadual de Santa Cruz (2010). E-mail: gardeniajardim.ftc@gmail.com 